\title{
Análise da dinâmica no uso da terra maranhense na Amazônia Legal
}

\section{Analysis of the dynamics in the use of Maranhão land in the Legal Amazon}

\author{
Carlos Augusto Alves Cardoso Silva ${ }^{1}$, Kamilla Andrade de Oliveira ${ }^{2}$, Maria Patrícia Pereira Castro ${ }^{3}$, \\ Ana Karla da Silva Oliveira ${ }^{4}$, Edmilson Igor Bernardo Almeida ${ }^{5}$, Washington da Silva Sousa ${ }^{6}$
}

${ }^{1}$ Graduando em Engenharia Agrícola, Universidade Federal do Maranhão, Chapadinha, (98) 8435-8666, carlosaugusto8435@gmail.com; 20outora em Meteorologia Agrícola, Universidade Federal do Maranhão, Chapadinha, , kamilla.andrade@ ufma.com.br; ${ }^{3}$ Graduanda em Zootecnia, Universidade Federal do Maranhão, mariapatriciacastro0512@gmail.com; ${ }^{4}$ Graduanda em Engenharia Agrícola, Universidade Federal do Maranhã, karlinha_oliveira95@hotmail.com: ${ }^{5}$ Doutor em Agronomia, Universidade Federal do Maranhão, edmilson_i@hotmail.com; ${ }^{6}$ Doutor em Física, Universidade Federa do Maranhão, wssousa@gmail.com

\section{A R T I G O}

Recebido: 30/04/2019

Aprovado: 24/06/2019

\section{Palavras-chave:}

Desmatamento

Bovinocultura

Agropecuária
Key words:

Deforestation

Cattle breeding

Farming

\section{R E S U M O}

Por muitos anos as produções agropecuárias foram as principais causas do desmatamento na Amazônia Legal, principalmente após as políticas desenvolvimentistas para região amazônica, a partir da década 60. Neste contexto, objetivou-se analisar no período de 2002 a 2017, a dinâmica espaço-temporal do uso e cobertura do solo nos municípios maranhenses situados na Amazônia Legal. O estudo aconteceu em 170 municípios que fazem parte do território da Amazônia Legal. Utilizou-se para aplicação do coeficiente de correlação, os dados referentes às áreas desmatadas, área total utilizada na agricultura e quantidade de bovinos. Empregou-se também os dados de área territorial e estimativa populacional dos municípios de maior área desmatada. Observou-se que o desmatamento na Amazônia Legal, no Maranhão, teve expressiva redução de 131.428 hectares, entre os anos de 2002 a 2017. Em contraste a isso, o número de bovinos e a área utilizada na agricultura aumentaram de 4,33 para 7,098 milhões e 1,052 para 1,573 milhões de hectares, respectivamente. O desmatamento da Amazônia Legal no Maranhão, em 16 anos, esteve amplamente (70\%) concentrado em 25 municípios, principalmente os localizados próximos a importantes rodovias federais ou com fácil acesso a outros estados, como o Pará. Embora, os indicadores de desmatamento na Amazônia Legal situada no Maranhão, indiquem que há redução em 16 anos, é necessário atentar ao desenvolvimento sustentável na agropecuária, ou seja, equilíbrio entre o econômico, ecológico e social, pois há muito que pode ser preservado, ainda. Também é importante a adequada fiscalização ambiental em áreas de divisa do estado, que demonstram uma forte tendência a impactos ambientais, associados ao desmatamento.

\section{A B S T R A C T}

For many years, crop and livestock production were the main causes of deforestation in the Amazon Region, mainly after the developmentalist policies for the Amazon region in the 60s. In this context, the objective was to analyze, from 2002 to 2017, the spatiotemporal dynamics of land use and land cover in Maranhão municipalities located in the Legal Amazon. The study took place in 170 municipalities that are part of the territory of the Legal Amazon. For the application of the correlation coefficient, data referring to deforested areas, total area used in agriculture and number of cattle were used. The data of territorial area and population estimation of the municipalities of larger deforested area were also used. Deforestation in the Legal Amazon in Maranhão was significantly reduced by 131,428 hectares from 2002 to 2017. In contrast, the number of cattle and the area used for agriculture increased from 4.33 to 7.098. million and 1.052 to 1.573 million hectares, respectively. Deforestation of the Legal Amazon in Maranhão, in 16 years, was largely (70\%) concentrated in 25 municipalities, mainly those located near important federal highways or with easy access to other states, such as Pará. Although, deforestation indicators in Legal Amazon located in Maranhão, indicate that there is a reduction in 16 years, it is necessary to pay attention to sustainable development in agriculture, that is, balance between the economic, ecological and social, because there is much that can still be preserved. Appropriate environmental oversight in state boundary areas, which show a strong tendency to environmental impacts associated with deforestation, is also important.

\section{Revista Verde}

ISSN 1981-8203

Pombal, Paraíba, Brasil v. 14, n.3, jul.-set, p.443-452, 2019

doi: 10.18378/rvads.v14i3.6550 


\section{INTRODUÇÃO}

A região Amazônica possui uma área de $5.217 .423 \mathrm{~km}^{2}$, equivalente aos estados do Acre, Amapá, Amazonas, Mato Grosso, Pará, Roraima, Rondônia, Tocantins e parcialmente, o estado do Maranhão ao oeste do Meridiano $44^{\circ}$, a área total corresponde por $61 \%$ do território nacional, a criação da Amazônia Legal e suas divisões foram decorrentes da lei de $\mathrm{n}^{\circ} 1.806$ de 06/01/1953 que teve como objetivo o desenvolvimento da região (MARTHA JÚNIOR et al., 2011).

Desde da década de 60 as políticas voltadas para o desenvolvimento da Amazônia brasileira tiveram caráter econômico, visando fortalecer a economia da região e uma maior ocupação territorial, sem planejamento e controle para alcançar um desenvolvimento sustentável. Essas ações desenvolvimentistas são observadas através das construções de redes rodoviárias, incentivos fiscais para estimular investimentos agropecuários e a migração regional (ALVES, 2002; BAER, 2009; ARRAES et al., 2012).

Em decorrência de alcançar maior desenvolvimento regional e rápida ocupação territorial, a partir dos anos 60 e 70 a extração da madeira e a presença de empresas do setor madeireiro aumentaram significativamente durante a década de 80 (VERÍSSIMO; PEREIRA, 2015), sendo um dos setores responsáveis pela devastação de grandes áreas com florestas da Amazônia Legal.

Nesse sentido, o desmatamento esteve dividido em dois recortes temporais: antes de 1980 e a partir de 1980. No primeiro recorte o desmatamento esteve relacionado com a abertura de estradas, incentivo de colonização, melhor organização da atividade agropecuária com vantagens de incentivos fiscais. O segundo recorte, foi caracterizado pelas ações do primeiro recorte, tendo em vista uma maior valorização econômica dos resultados dos setores de exploração dos recursos naturais, principalmente as atividades madeireiras e a pecuária extensiva (DINIZ et al., 2009).

Em decorrência do aumento do desmatamento, no ano de 2004 foi criado o Plano de Ação para Prevenção e Controle do Desmatamento na Amazônia Legal (PPCDAm), com a finalidade de reduzir o desmatamento de forma mais acentuada e continua, sem esquecer de promover um desenvolvimento sustentável na Amazônia Legal (BRASIL, 2012).

No entanto, as políticas contra o desmatamento da Amazônia Legal instigaram dois argumentos sobre o desenvolvimento regional: o primeiro retratava sobre uma possível diminuição do desenvolvimento econômico, devido o impedimento do aumento da produção agropecuária; e o segundo, que era possível aumentar a produção e reduzir o desmatamento, utilizando áreas que já haviam sido desmatadas. (BARRETO; SILVA 2013).

Em relação aos meios de produção na Amazônia Legal, a pecuária é a que mais se destacou, devido seu crescimento ao longo dos anos, principalmente a bovinocultura que passou de 37,16 milhões em 1995 para 80,29 milhões em 2013 (ASSAD, 2016). No entanto, esse crescimento esteve com alta correlação com o desmatamento até meados dos anos 2000 a 2006 (RIVERO et al., 2009; MARGULIS 2003). Mas, a partir de 2007 a pecuária continuou crescendo e o desmatamento reduzindo, ocorrendo uma correlação negativa (BARRETO; SILVA 2013).
Estudos realizados por Brum et al. (2011) relacionados ao desmatamento na Amazônia Legal, no período de 2000 a 2009, mostraram que houve maiores incrementos de áreas desmatadas nos anos de 2000 a 2005, sendo 2004 o mais expressivo que os demais, através das fiscalizações mais acentuadas, no período de 2006 a 2009 foram os anos que apresentaram uma menor área desmatada.

Além disso, dados gerados pelo o Projeto de Monitoramento do Desmatamento na Amazônia Legal (PRODES), indicaram que o desmatamento na Amazônia Legal no período de agosto de 2016 a julho de 2017 alcançou $6.947 \mathrm{~km}^{2}$, possuindo uma redução de $12 \%$ em relação a 2016 $\left(7.893 \mathrm{~km}^{2}\right)$ e de $75 \%$ correspondente ao ano de 2004 . Além disso, os estados de maiores áreas desmatadas nos anos de 2002 a 2017, foram: Pará (38,77\%), Mato Grosso (29,62\%), Rondônia (12,89\%), Amazonas (6,22\%), Maranhão (5,74\%), Acre $(3,41 \%)$, Roraima (1,96\%), Tocantins $(0,81 \%)$ e Amapá $(0,58 \%)$ (INPE, 2019).

No que se refere ao desmatamento no estado do Maranhão, segundo estudos realizados pela SEMA (2011), o desmatamento acumulado até o ano de 2009 foi de 101.521 $\mathrm{km}^{2}$, os dados revelaram que o ano 1988 foi o mais expressivo em áreas desmatadas no período de 1998 a 2010, entre os anos 2002 a 2009 o estado evidenciou alguns municípios que obtiveram incrementos de desmatamento entre $90 \mathrm{~km}^{2}$ e $400 \mathrm{~km}^{2}$, correspondendo a percentuais crescentes.

Apesar da redução do desmatamento na Amazônia brasileira ao longo dos anos, sabe-se ainda muito pouco sobre a contribuição do estado do Maranhão em relação a tal causa, possuindo poucos estudos que retratam sobre o assunto. Além disso, poucos trabalhos abordam sobre as causas do desmatamento nos municípios do estado e quais se destacam pela quantidade de área desmatada.

Em virtude disto, objetivou-se em analisar a dinâmica espaço-temporal do uso e cobertura do solo dos municípios maranhense situados na Amazônia Legal no período de 2002 a 2017, através da aplicação do coeficiente de correlação entre o desmatamento, área total utilizada na agricultura e o quantitativo de bovinos, evidenciando os municípios de maior área desmatada no período analisado.

\section{MATERIAL E MÉTODOS}

A pesquisa foi realizada no território amazônico, referente ao estado do Maranhão, que é parcialmente coberto ao Oeste do meridiano $44^{\circ}$ (SUDAM, 2016), conforme a figura 1.

Segundo o Instituto Brasileiro de Geografia e Estatísticas - IBGE, a Amazônia Legal no estado do Maranhão é constituída por 181 municípios. No entanto, 11 municípios localizam-se na linha do limite da Amazônia Legal (figura 1), não fazendo parte do território analisado por completo, os municípios de: Buriti Bravo, Cachoeira Grande, Codó, Itacu, Morros, Paraibano, Presidente Vargas, São João do Soter, Senador Alexandre Costa, Timbiras e Vargem Grande. Nesse sentido, o estudo referiu-se somente aos 170 municípios que fazem parte por total do território Amazônico. 
Figura 1. Localização da área de estudo, Amazônia Legal no estado do Maranhão, Brasil.

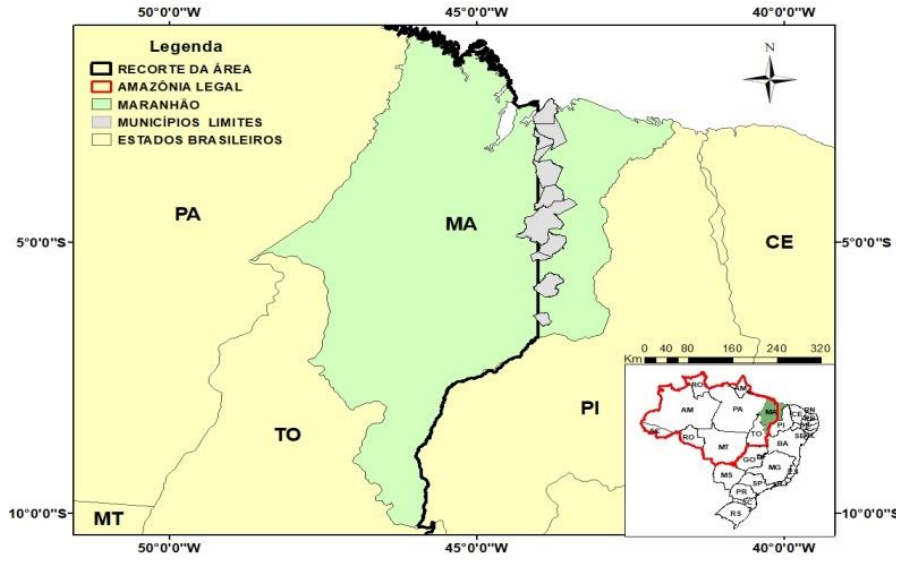

Fonte: elaborado pelo autor através de dados do IBGE, 2019.

O clima na Amazônia Legal segundo Koppen é caracterizado em equatorial e tropical, os estados do Amazonas, Pará, Acre, Rondônia, Amapá, norte do Mato Grosso e oeste de Roraima predomina-se o clima equatorial, que é marcado durante todo ano por alta umidade e elevadas temperaturas. O clima tropical é constatado no Centro e Sul do Mato Grosso, em Tocantins e ao leste de Roraima, com temperaturas em médias de $20^{\circ} \mathrm{C}$ e amplitudes que não excedem $10^{\circ} \mathrm{C}$ (ASSAD, 2016).

No perímetro da Amazônia Legal para o ano de 2013 havia 6.801.826 habitantes, havendo um grande crescimento, em relação ao censo de 2000, onde esse número era de apenas 5.651.475 de pessoas, o território possuía uma densidade de $20,49 \mathrm{hab} / \mathrm{km}^{2}$ para o ano de 2013 e uma taxa de crescimento de $6,37 \%$ entre 2010 a 2013 (SUDAM, 2016).

Utilizou-se como referência as informações coletadas ao banco de dados do Instituto Brasileiro de Geografia e Estatísticas (IBGE), especificamente no acervo da plataforma SIDRA. Foram adquiridos os dados de área plantada na agricultura das culturas permanente e temporária, rebanho de bovinos, área territorial e população estimada para o ano de 2017.

Figura 2. Área plantada (100 ha), desmatamento (ha) e criação de bovinos em áreas da Amazônia legal no período de 2002 a 2017, estado do Maranhão.
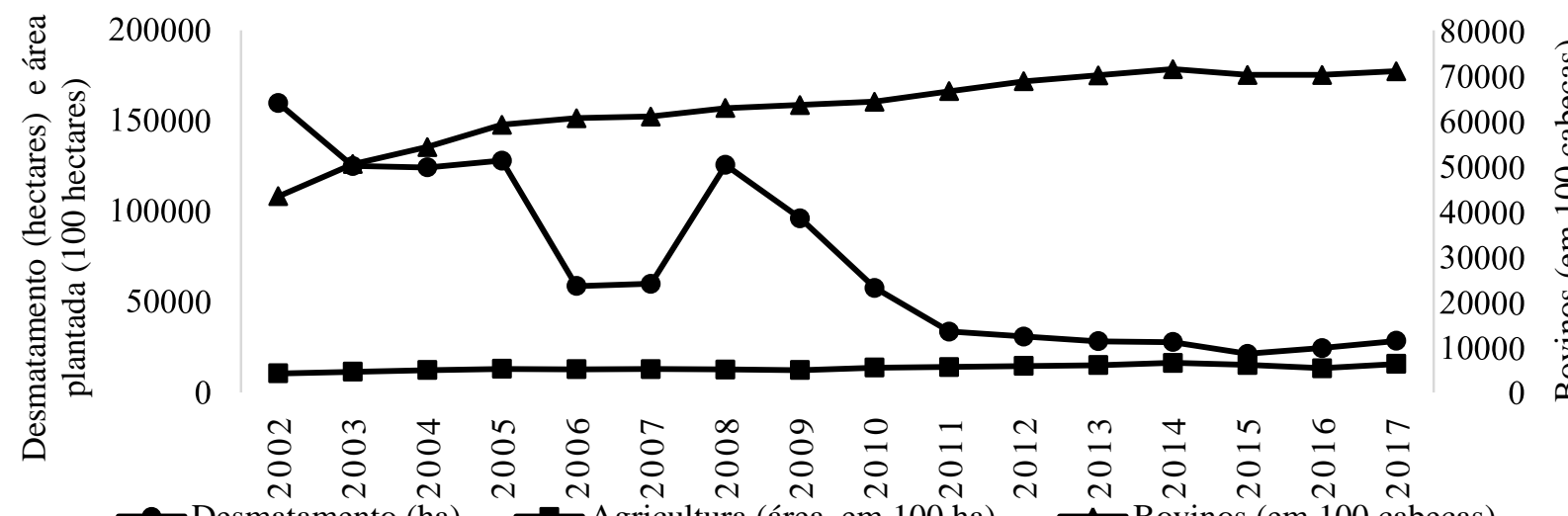

Fonte: Elabora pelo autor através de dados do IBGE, 2019 e INPE, 2019.

Ao analisar o desmatamento na extensão da Amazônia Legal maranhense é notável que o ano de 2002 (159.890 ha) foi o que gerou um maior quantitativo, possuindo reduções expressivas nos anos de 2006 (58.720 ha) e 2007 (60.050 ha),
Fez-se necessário o uso de dados em relação ao incremento do desmatamento nos anos de 2002 a 2017, sendo obtidos através do Projeto de Estimativa do Desflorestamento da Amazônia - PRODES, responsável pela mensuração do desmatamento da Amazônia Legal desde de 1988 (INPE, 2019). Os valores utilizados no estudo foram concernentes ao desmatamento por município que compõem o território amazônico maranhense.

O trabalho avaliou se existe uma correlação no período de 2002 a 2017 entre as variáveis: áreas desmatadas, quantidade de bovinos e área usada na agricultura das culturas permanentes e temporárias. Para análise de correlação, utilizou-se o coeficiente de Pearson, com o auxílio do software Excel@, como é descrito na equação 1:

$$
\rho=\frac{\sum_{i=1}^{n}\left(x_{i}-\bar{x}\right)\left(y_{i}-\bar{y}\right)}{\sqrt{\sum_{i=1}^{n}\left(x_{i}-\bar{x}\right)^{2}} * \sqrt{\sum_{i=1}^{n}\left(y_{i}-\bar{y}\right)^{2}}}=\frac{\operatorname{cov}(X, Y)}{\sqrt{\operatorname{var}(X) * \operatorname{var}(Y)}}
$$

Em que $x_{1}, x_{2}, \ldots, x_{n}$ e $y_{1}, y_{2}, \ldots y_{n}$ os valores medidos de ambas as variáveis. Enquanto, $\bar{x}=\frac{1}{n} * \sum_{i=1}^{n} x_{i}$ e $\bar{y}=\frac{1}{n} *$ $\sum_{i=1}^{n} y_{i}$ são as médias aritméticas de ambas as variáveis.

O coeficiente de correlação possui como função, medir o grau de correlação entre duas variáveis, apresentando valores que variam entre 1 (correlação positiva) a -1 (correlação negativa).

Além disso, o estudo enfatizou os municípios que mais contribuíram com o desmatamento em 16 anos, enfatizando as possíveis causas que podem ter levado a abertura de novas áreas.

\section{RESULTADOS E DISCUSSÃO}

A área desmatada na Amazônia legal no Estado do Maranhão nos últimos 16 anos, apresentou maior crescimento no ano de 2002, tendo reduções de áreas nos anos subsequentes. Além disso, nota-se que a superfície usada nas plantações temporárias e permanentes se manteve praticamente estável sem grandes aberturas de novas áreas, no entanto houve um aumento no rebanho de bovinos na região da Amazônia Legal no período de 2002 a 2017 (Figura 2). 
menores taxas de áreas desmatadas ocorreram a partir do ano de 2009 (96.180 ha), sendo os anos de 2011 (33.560 ha) a 2017 (28.462 ha) os mais significativos na redução de florestas devastadas.

Estudos realizados por Brum et al. (2011), na Amazônia Legal revelam que o estado do Maranhão teve maiores áreas desmatadas nos anos 2000 e 2002 respectivamente, os autores relatam uma redução mais expressiva no desmatamento na Amazônia Legal brasileira entre os anos de 2005 a 2007, no período de 2000 a 2007. Corroborando com os resultados de Castelo et al. (2018), onde destacam uma redução no desmatamento a partir de 2004 em todos os estados da Amazônia Legal entre 2002 a 2016.

Segundo Ferreira e Coelho (2015), o desmatamento na Amazônia a partir de 2009 apresenta as maiores baixas em relação à anos anteriores, continuando em queda nos anos subsequentes, estando essas baixas relacionadas com o período de desenvolvimento das políticas públicas ao combate do desmatamento, sendo aplicadas de forma mais precisa.

Diferente do desmatamento que teve grandes oscilações em áreas em 16 anos, a área de plantação utilizada na agricultura temporária e permanente não teve abertura expressiva de novas áreas, tendo em vista que a área era de 1,052 milhões de hectares em 2002, aumentando para 1,573 milhões de hectare no ano de 2017 (figura 2). Equiparando-se com os resultados de Santos e Queiroz (2014), quando retratam uma diminuição nas curvas de desmatamento e áreas plantadas nos anos de 1995 a 2011.

Ao analisar o desmatamento e a área plantada é visível que há uma forte correlação negativa $(-0,84)$, no entanto, no período analisado não houve influência da área plantada no aumento do desmatamento. Evidenciou-se que por mais que as áreas desmatadas tenham diminuído e, não houve aumento de área muito expressiva na agricultura.

Em relação à criação de bovinos na Amazônia Legal que estabeleceu aumentos expressivos no número de animais, passando de 4,33 milhões para 7,098 milhões de cabeça nos anos de 2002 a 2017 (figura 2). Apesar do aumento notou-se que o desmatamento permaneceu em decréscimo nos últimos anos. Estando em concordância com os resultados de Assad (2016), quando relata uma crescente expansão da bovinocultura na Amazônia Legal, juntamente com uma significativa redução do desmatamento na região no período de 1995 a 2013.

Não somente, estudos revelam que o maior problema não se trata da pecuária em si, mas sim pela falta de maiores investimentos e uso de novas tecnologias no processo de produção (RETTMANN, 2013). Barreto e Silva (2013), destacam que entre os anos de 2007 e 2010, o valor da produção do setor agropecuária cresceu, enquanto o desmatamento reduziu, ocorrendo uma correlação negativa. Além disso, Arima et al. (2005) e Alencar et al. (2004), relatam que entre 2002 e 2003 a pecuária teve grandes avanços tendo como os principais fatores a melhor produtividade resultante de boas condições agroclimáticas e preços das terras relativamente baixo.

Dos 170 municípios analisados, o desmatamento da Amazônia Legal no Maranhão de 2002 a 2017 esteve concentrado $70 \%$ em 25 municípios, como exposto na figura 3.

Figura 3. Os 25 municípios que possuem 70\% do desmatamento da Amazônia legal no estado do Maranhão de 2002 a 2017.

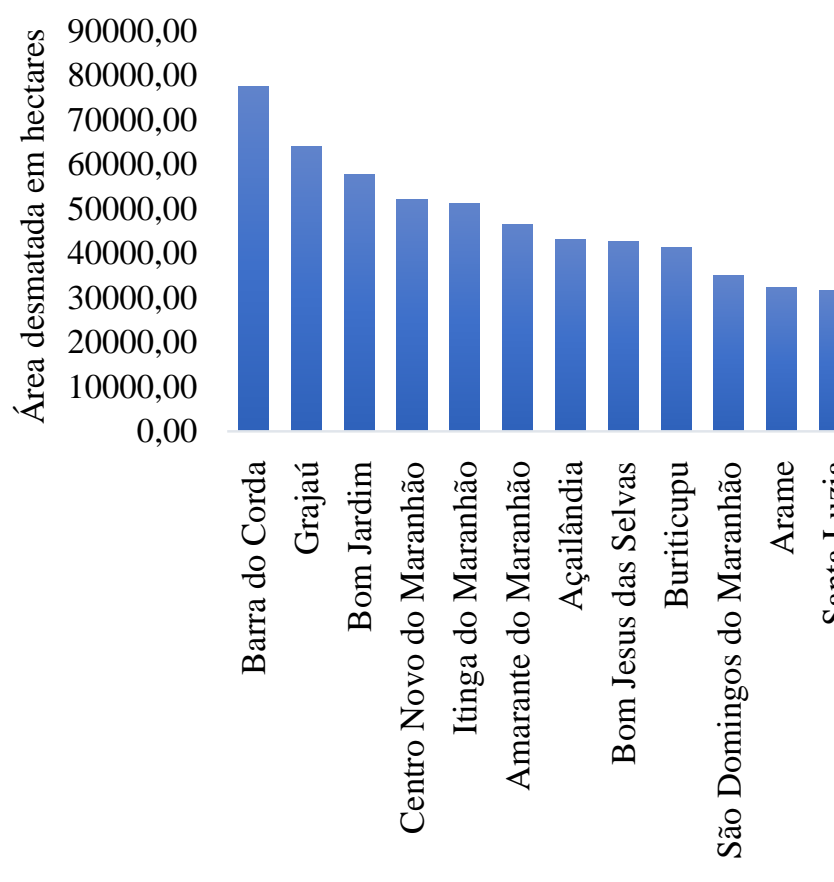

Os municípios Barra do Corda e Grajaú foram os que registraram os maiores valores de áreas desmatadas em 16 anos, com um total de 77.504 hectares $(6,86 \%)$ e 64.116 hectares $(5,67 \%)$, respectivamente. Enquanto isso, os municípios de Zé Doca, Cândido Mendes, São Luís, Centro do Guilherme, Fortuna, Amapá do Maranhão, Governador Luiz Rocha, Jenipapo dos Vieiras e Buritirana revelaram valores de áreas desmatadas que variaram entre 16.860 hectares a 12.403 hectares e com percentual de 1,49\% a $1,10 \%$. Os demais municípios que fazem parte da Amazônia Legal no Estado e que foram analisados registraram valores abaixo de $1 \%$.

Em um estudo sobre o desmatamento na Amazônia Legal no Maranhão, 20 municípios destacaram-se como os de maiores áreas desmatadas no período de 2002 a 2009, sendo eles: Açailândia, Amapá do Maranhão, Amarante do 
Maranhão, Arame, Barra do Corda, Buritirana, Centro Novo do Maranhão, Fortuna, Gonçalves Dias, Governador Eugênio Barros, Itapecuru Mirim, Santa Luzia, São Domingos do Maranhão, Tuntum, Buriticupu, Bom Jardim, Itinga do Maranhão, Grajaú, Bom Jesus das Selvas e Cândido Mendes. Os municípios Amarante do Maranhão e Grajaú passaram a integrar a lista dos maiores devastadores da Amazônia legal no estado do Maranhão no período de 2010 a 2011 (SEMA, 2011), assemelhando-se com os resultados exposto na figura 3. Tais resultados enfatizam que os munícipios em destaque permaneceram em alta com o desmatamento.

Tabela 1. Área territorial, área desmatada em 16 anos e percentual da área desmatada em relação a área total de municípios da Amazônia Legal no estado o Maranhão, Brasil.

\begin{tabular}{|c|c|c|c|}
\hline Municípios & Área Territorial (ha) & Área Desmatada (ha) & Percentual (\%) \\
\hline Barra do Corda & 520270 & 77504 & $14,90 \%$ \\
\hline Grajaú & 883090 & 64116 & $7,26 \%$ \\
\hline Bom Jardim & 659050 & 57678 & $8,75 \%$ \\
\hline Centro Novo do Maranhão & 825840 & 52024 & $6,30 \%$ \\
\hline Itinga do Maranhão & 358170 & 51260 & $14,31 \%$ \\
\hline Amarante do Maranhão & 743800 & 46535 & $6,26 \%$ \\
\hline Açailândia & 580640 & 43003 & $7,41 \%$ \\
\hline Bom Jesus das Selvas & 267910 & 42606 & $15,90 \%$ \\
\hline Buriticupu & 254560 & 41272 & $16,21 \%$ \\
\hline São Domingos do Maranhão & 115200 & 34907 & $30,30 \%$ \\
\hline Arame & 300870 & 32326 & $10,74 \%$ \\
\hline Santa Luzia & 476610 & 31636 & $6,64 \%$ \\
\hline Tuntum & 339000 & 26069 & $7,69 \%$ \\
\hline Gonçalves Dias & 87850 & 23673 & $26,95 \%$ \\
\hline Itapecuru Mirim & 147140 & 20212 & $13,74 \%$ \\
\hline Governador Eugênio Barros & 81700 & 20091 & $24,59 \%$ \\
\hline Zé Doca & 241610 & 16860 & $6,98 \%$ \\
\hline Cândido Mendes & 163370 & 15868 & $9,71 \%$ \\
\hline São Luís & 83480 & 15787 & $18,91 \%$ \\
\hline Centro do Guilherme & 107410 & 15399 & $14,34 \%$ \\
\hline Fortuna & 69500 & 14982 & $21,56 \%$ \\
\hline Amapá do Maranhão & 50240 & 14053 & $27,97 \%$ \\
\hline Governador Luiz Rocha & 37320 & 13570 & $36,36 \%$ \\
\hline Jenipapo dos Vieiras & 196290 & 13545 & $6,90 \%$ \\
\hline Buritirana & 81840 & 12403 & $15,16 \%$ \\
\hline
\end{tabular}

Fonte: elaborado pelo autor através de dados do IBGE, 2019 e INPE, 2019.

Os municípios de maior área territorial foram: Grajaú (883.090 ha), Centro Novo do Maranhão (825.840 ha), Amarante do Maranhão (743.800 ha), Bom Jardim (659.050 ha), Açailândia (580.640 ha) e Barra do Corda (520.270 ha). Consequentemente, Barra do Corda, Grajaú, Bom Jardim e Centro Novo do Maranhão destacaram-se pelos altos valores de áreas desmatadas (Tabela 1). Portanto, tais resultados enfatizam que o desmatamento pode estar relacionado também com a área territorial do município, ou seja, quanto maior for à área territorial, pode ocorrer um maior desmatamento. Rivero et al. (2009), retrataram que nos estados do Pará e Amazonas os municípios que registraram altas taxas de desmatamento, possuíam em geral áreas totais muito grandes.

Em termos percentuais, destacaram-se os municípios de Governador Luiz Rocha, São Domingos do Maranhão, Amapá do Maranhão, Gonçalves Dias e Governador Eugênio Barros com valores de 36,36\%, 30,30\%, 27,97\%, 26,95\% e $24,59 \%$, respectivamente. Esses valores enfatizam o quanto representa as áreas desmatadas em 16 anos na área total do município.

Para uma análise das possíveis causas do desmatamento nos municípios em questão, a Tabela 2 apresenta valores referentes à população estimada, criação de bovinos (em cabeças) e área plantada (hectares) das culturas permanentes e temporárias.

Em relação à população, os municípios de São Luís, Açailândia, Barra do Corda, Buriticupu e Santa Luzia retrataram uma maior estimativa populacional para o ano de 2017, com valores de 1.091.868 (hab), 111.339 (hab), 87.135 (hab), 71.979 (hab) e 71.576 (hab), respectivamente. O município de São Luís destacou-se pelo um maior crescimento populacional em 16 anos, com um aumento de 185.301 habitantes. Além disso, a área de produção agrícola reduziu nesse mesmo período, podendo ter ocorrido influência da expansão urbana.

Segundo Diniz et al. (2009), retratam que quanto maior o contingente populacional e a densidade demográfica, acredita-se que haja um maior desmatamento, os mesmos autores explicam que à medida que uma população aumenta há uma maior pressão sobre os recursos naturais. Corroborando com resultados de Brum et al. (2011), onde revelam que o aumento populacional apesar de menor escala, foi um dos fatores que esteve relacionado com o desmatamento no município de Sinop-MT, no sentido de crescimento do espaço urbano. 
Tabela 2. População estimada, quantidade de bovinos e área plantada das culturas permanentes e temporárias de municípios da Amazônia Legal no estado do Maranhão, Brasil. Os dados são referentes aos anos de 2002 e 2017.

\begin{tabular}{|c|c|c|c|c|c|c|}
\hline \multirow{2}{*}{ Municípios } & \multicolumn{2}{|c|}{ População Estimada (hab) } & \multicolumn{2}{|c|}{ Bovinos (cabeças) } & \multicolumn{2}{|c|}{ Área Plantada (ha) } \\
\hline & 2002 & 2017 & 2002 & 2017 & 2002 & 2017 \\
\hline Açailândia & 93455 & 111339 & 368466 & 323636 & 4221 & 27137 \\
\hline Amapá do Maranhão & 5771 & 6895 & 5301 & 11667 & 1701 & 1462 \\
\hline Amarante do Maranhão & 33015 & 41106 & 85231 & 262724 & 10245 & 3885 \\
\hline Arame & 28985 & 32145 & 58919 & 139046 & 14883 & 12369 \\
\hline Barra do Corda & 78468 & 87135 & 45152 & 129077 & 17110 & 10925 \\
\hline Bom Jardim & 35577 & 41120 & 75538 & 160491 & 12480 & 13328 \\
\hline Bom Jesus das Selvas & 17409 & 34278 & 40608 & 127856 & 5214 & 8113 \\
\hline Buriticupu & 55405 & 71979 & 41365 & 138520 & 13663 & 20260 \\
\hline Buritirana & 14341 & 15180 & 28095 & 60422 & 3662 & 305 \\
\hline Cândido Mendes & 17730 & 19943 & 12771 & 4438 & 7297 & 2265 \\
\hline Centro do Guilherme & 6408 & 13555 & 8029 & 24321 & 3979 & 2874 \\
\hline Centro Novo do Maranhão & 15098 & 21565 & 9418 & 90608 & 5412 & 3137 \\
\hline Fortuna & 14391 & 15262 & 16484 & 33557 & 10225 & 3155 \\
\hline Gonçalves Dias & 16844 & 17586 & 18029 & 31750 & 5619 & 1370 \\
\hline Governador Eugênio Barros & 14981 & 16582 & 9374 & 24944 & 5769 & 3624 \\
\hline Governador Luiz Rocha & 6466 & 7708 & 5412 & 10925 & 3254 & 3157 \\
\hline Grajaú & 49089 & 69232 & 79601 & 173239 & 14293 & 26801 \\
\hline Itapecuru Mirim & 50532 & 67726 & 18688 & 17216 & 9150 & 5978 \\
\hline Itinga do Maranhão & 24832 & 25589 & 113588 & 106549 & 9008 & 13933 \\
\hline Jenipapo dos Vieiras & 10241 & 16321 & 20253 & 61575 & 7290 & 2959 \\
\hline Santa Luzia & 73177 & 71576 & 87721 & 231658 & 25139 & 16755 \\
\hline São Domingos do Maranhão & 34182 & 33691 & 23517 & 56970 & 16154 & 5406 \\
\hline São Luís & 906567 & 1091868 & 890 & 1734 & 199 & 148 \\
\hline Tuntum & 35992 & 41342 & 47957 & 116831 & 11386 & 9243 \\
\hline Zé Doca & 47794 & 51084 & 42859 & 135189 & 7865 & 6124 \\
\hline
\end{tabular}

Fonte: elaborado pelo autor através de dados do IBGE, 2019.

Dentre os municípios de maior rebanho bovino no ano de 2017, destacaram-se: Açailândia (323.636 cabeças), Amarante do Maranhão (262.724 cabeças), Santa Luzia (231.658 cabeças), Grajaú (173.239 cabeças) e Bom Jardim (160.491 cabeças. No entanto, Açailândia e Itinga do Maranhão registraram uma redução no período de 2002 a 2017, passando de 368.466 para 323.636 e 113.588 para 106.549 animais, respectivamente.

Esses quantitativos podem ser explicados pelo fato que os anos de 2001, 2002 e 2003 foram marcados por políticas de incentivos de desenvolvimento, por maiores facilidades de compras de terras e também pelas maiores facilidades de substituição de florestas por pastagens. Segundo Alencar et al. (2004), a pecuária na Amazônia Legal em 2001 representava $29 \%$ do rebanho nacional, sendo motivado em partes pela disponibilidade de capital para investimentos, como também pela expansão do mercado internacional e nacional de carne e leite. Além disso, os avanços da pecuária nos anos de 2002 e 2003 podem ser associados também, pelo baixo custo de terras (ALENCAR et al., 2004; ARIMA et al., 2005).

Além disso, segundo Pantoja e Pereira (2017), a produção de eucalipto cresceu significativamente nos municípios em questão na última década, principalmente após a chegada da empresa Suzano Papel e Celulose na região.

Mesmo com o aumento da pecuária em praticamente quase todos os municípios, houve uma redução expressiva no desmatamento da Amazônia Legal maranhense. Pesquisas mostram que em alguns casos a forma de manejo bovina foi uma das principais causas para expansão de áreas desmatadas, fatos que vem melhorando em relação ao manejo e criação desses animais. De acordo com Rivero et al. (2009); Margulis (2003); a pecuária bovina (gado) é atividade que mais está relacionada com o desmatamento para os municípios da Amazônia legal com uma grande correlação entre a quantidade de animais (bovinos) com o desmatamento.

Os municípios de maior área plantada foram: Açailândia (27.137 ha), Grajaú (26.801 ha), Buriticupu (20.260 ha), Santa Luzia (16.755 ha) e Intiga do Maranhão (13.933 ha). A área utilizada na agricultura diferente das demais variáveis analisadas que aumentaram em 16 anos (população estimada e rebanho de bovinos), registrou uma redução, sendo na maioria dos municípios o ano de 2002 alcançou uma maior área que 2017. Dos 25 municípios analisados, 18 registraram uma redução de área, sendo eles: Amapá do Maranhão, Amarante do Maranhão, Arame, Barra do Corda, Buritirana, Centro do Guilherme, Centro Novo do Maranhão, Fortuna, Gonçalves Dias, Governador Eugênio Barros, Governador Luiz Rocha, Itapecuru Mirim, Jenipapo dos Vieiras, Santa Luzia, São Domingos do Maranhão, São Luís, Tuntum e Zé Doca.

Acredita-se que parte dessas áreas foram destinadas a outros meios de produção, como por exemplo: pastagens, plantações de eucalipto ou até mesmo por ocasiões da expansão urbana motivado pelo o aumento populacional.

Oliveira et al. (2018), retratam que houve um significativo aumento na produção de eucalipto no Estado, os municípios de Itinga do Maranhão, Bom Jardim, Bom Jesus das Selvas, Açailândia, Grajaú, dentre outros, foram responsáveis por parte da produção de eucalipto no ano de 2015 para empresa Suzano Papel e Celulose. Possuindo uma das principais rotas para o escoamento da produção a BR- 222 que liga o município de Estreito a São Luís, figura 4.

Com objetivo de se extrair maiores informações sobre as causas do desmatamento, realizou-se um mapa dos 25 
municípios que apresentaram os maiores índices de áreas

devastadas no estado.

Figura 4. Mapa referente aos 25 municípios de maior incremento de área desmatada no período de 2002 a 2016 , rodovias e o corte da Amazônia no estado do Maranhão.

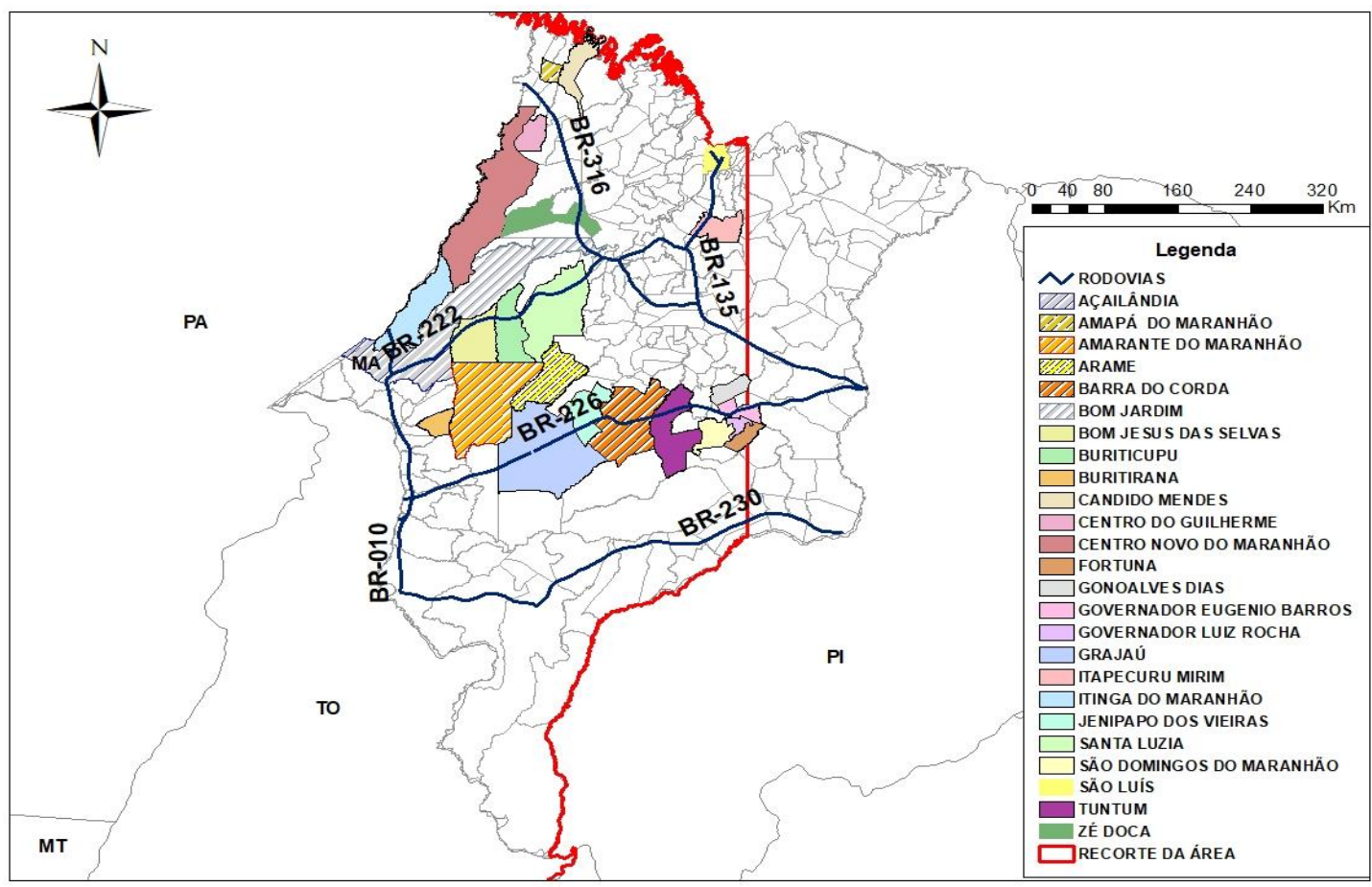

Fonte: elaborado pelo autor através de dados do IBGE, 2019.

Ao analisar os municípios em questão notou-se que muitos compartilham de características em comum, a maioria dos municípios são interligados ou ficam próximos de rodovias importantes do Estado, como a BR-226, BR-222 e a BR-316. Podendo ser explicado pela maior facilidade que os municípios possuem para realizarem o escoamento da produção. Além disso, as BR- 222 e 135 fazem conexão até o porto do Itaqui em São Luís- MA, passando a ser um importante mecanismo para transportação da produção agrícola.

Em 2016, o porto do Itaqui foi responsável por movimentar um total de 17,1 milhões de toneladas. Os produtos agrícolas de maior embarque foram: soja (3.849.776 t), celulose $(1.375 .602 \mathrm{t})$, milho $(638.860 \mathrm{t})$ e farelo de soja $(152.998 \mathrm{t})$. E os de maior desembarque, foram: fertilizantes (638.860 t), trigo (87.393 t) e arroz (43.052 t) (MTPA, 2019).

Outro aspecto importante entre os municípios refere-se à localização, em quase toda a totalidade são vizinhos, além disso, houve uma maior concentração de municípios próxima à fronteira com o Estado do Pará (figura 4), sendo possível a ocorrência de influência de um sobre o outro em relação ao meio de produção e consequentemente a abertura de novas áreas.

Segundo Alencar et al. (2004), os estados do Pará, Mato Grosso e Rondônia foram os campeões de desmatamento, estando o estado do Pará com a segunda posição de maior rebanho bovino no período de 1990 a 2001. Além disso, o rebanho bovino cresceu significativamente nos anos de 2001 a 2010, sendo um dos fatores de maior correlação com o desmatamento no estado do Pará (CASTELO; ALMEIDA, 2015).

Esses resultados enfatizam que os fatores e agentes causadores do desmatamento podem ser ou ocorrer das mais diversas formas possíveis, possuindo grandes diferenças dependo da localização em questão (FEARNSIDE, 2008).

Embora, os indicadores de desmatamento na Amazônia Legal situada no Maranhão, indiquem que há redução em 16 anos, é necessário atentar ao desenvolvimento sustentável na agropecuária, ou seja, equilíbrio entre o econômico, ecológico e social, pois há muito que pode ser preservado, ainda. Também é importante a adequada fiscalização ambiental em áreas de divisa do estado, que demonstram uma forte tendência a impactos ambientais, associados ao desmatamento.

\section{CONCLUSÃO}

O desmatamento na Amazônia Legal, no estado do Maranhão, teve expressiva redução de $82 \%$, entre os anos de 2002 a 2017. Em contraste a isso, neste mesmo período o número de bovinos e a área utilizada na agricultura aumentaram $39 \%$ e $33 \%$, respectivamente.

O desmatamento da Amazônia Legal no Maranhão, em 16 anos, esteve concentrado em 25 municípios, principalmente os localizados próximos a importantes rodovias federais ou com fácil acesso a estados fronteiriços.

\section{REFERÊNCIAS}

ALENCAR, A. D.; NEPSTAD, D.; MCGRATH, P.; MOUTINHO, P.; PACHECO, M. C.; SOARES FILHO, V. D. Desmatamento na Amazônia: indo além da emergência crônica. Instituto de Pesquisas Ambientais da Amazônia (IPAM), Belém, Brasil, 2004.

ALVES, D. S. Space-time dynamics of deforestation in Brazilian Amazonia. International Journal of Remote Sensing, 
v. 23, n. 14, p. 2903-2908, $10.1080 / 01431160110096791$.

ARIMA, E.; BARRETO, P.; BRITO, M. Pecuária na amazônia: tendências e implicações para a conservação ambiental, Technical report, Instituto do Homem e Meio Ambiente da Amazônia, 1. ed., 2005.

ARRAES, R. D. A.; MARIANO, F. Z.; SIMONASSI, A. G. Causas do desmatamento no Brasil e seu ordenamento no contexto mundial. Revista de Economia e Sociologia Rural, v. $50, \quad$ n. $1, \quad$ p. $119-140, \quad 2012$. 10.1590/S010320032012000100007.

ASSAD, E. D. Amazônia legal: propostas para uma exploração agrícola sustentável (relatório completo). Escola de Economia de São Paulo (EESP), 2016.

BAER, W. A economia brasileira. 3. ed. ampliada e revisada. São Paulo: Nobel, 2009.

BARRETO, P.; SILVA, D. Como desenvolver a economia rural sem desmatar a Amazônia? Imazon. Belém. 2013.

BRASIL. Mistério do meio Ambiente. Plano de Ação para Prevenção e Controle do Desmatamento na Amazônia Legal, Brasília, 2012. Disponível em <http://www.mma.gov.br/informma/item/616preven $\% \mathrm{C} 3 \% \mathrm{~A} 7 \% \mathrm{C} 3 \% \mathrm{~A} 30-\mathrm{e}-$ controle-do-desmatamento-naamaz\%C3\%B4nia.html>. Acesso em: 28/fev/2019.

BRUM, A. L.; TIVES DALFOVO, W. C.; BENFICA, V. C. A relação entre o desmatamento e o crescimento das culturas de grãos no município de Sinop-MT: Uma análise para o período de 1984 a 2009. Desenvolvimento em Questão, v. 9, n. 17, 2011.

CASTELO, T. B.; ALMEIDA, O. T. D. Desmatamento e uso da terra no Pará. Revista de política agrícola, v. 24, n. 1, p. 99-111, 2015.

CASTELO, T. B., ADAMI, M., ALMEIDA, C. A., ALMEIDA, T, O. Governos e mudanças nas políticas de combate ao desmatamento na Amazônia. REVIBECREVISTA IBEROAMERICANA DE ECONOMÍA ECOLÓGICA, p. 125-148, 2018.

DINIZ, M. B.; OLIVEIRA JUNIOR, J. N. D.; TROMPIERI NETO, N.; DINIZ, M. J. T. Causas do desmatamento da Amazônia: uma aplicação do teste de causalidade de Granger acerca das principais fontes de desmatamento nos municípios da Amazônia Legal brasileira. Nova Economia, v. 19, n. 1, p. 121-151, 2009. 10.1590/S0103-63512009000100006.

FEARNSIDE, P. M. Amazon forest maintenance as a source of environmental services. Anais da Academia Brasileira de Ciências, v. 80, n. 1, p. 101-114, 2008. 10.1590/S000137652008000100006.

FERREIRA, M. D. P.; COELHO, A. B. Desmatamento Recente nos Estados da Amazônia Legal: uma análise da contribuição dos preços agrícolas e das políticas governamentais. Revista de Economia e Sociologia Rural, v.
53, n. 1, p. 91-108, 2015. 10.1590/1234-567818069479005301005 .

IBGE, Instituto Brasileiro de Geografia e Estatística. Acervo. Disponível em: <https://sidra.ibge.gov.br/acervo\#/S/Q〉. Acesso em: 11/fev/2019.

IBGE, Instituto Brasileiro de Geografia e Estatísticas. Geografia. Disponível em <https://ww2.ibge.gov.br/home/geociencias/geografia/amazo nialegal.shtm>. Acesso em: 24/Jan/2019.

INPE, Instituto Nacional de Pesquisa Espaciais. Desmatamento nos municípios. Disponível em: <http://www.dpi.inpe.br/prodesdigital/prodesmunicipal.php >. Acesso em: 28/fev/2019.

INPE, Instituto Nacional de Pesquisa Espaciais. Notícias: INPE registra $6.947 \mathrm{~km} 2$ de desmatamento na Amazônia em $2017 . \quad$ Disponível em: <http://www.obt.inpe.br/OBT/noticias/inpe-registra-6-947-

km2-de-desmatamento-na-amazonia-em-2017>. Acesso em: 06/fev/2019.

MARGULIS, S. Causas do desmatamento da Amazônia Brasileira. 1.ed. Brasília: Banco Mundial, 2003. 100 p.

MARTHA JÚNIOR, G. B.; CONTINI, E.; NAVARRO, Z. Caracterização da Amazônia Legal e macrotendências do ambiente externo. 1.ed. Embrapa Estudos e CapacitaçãoDocumentos (INFOTECA-E), 2011

MTPA. Ministérios dos Transportes, Portos e Aviação Civil. Plano mestre do complexo portuário do Itaqui. Disponível em:

<http://www.transportes.gov.br/images/SNP/planejamento_p ortuario/planos mestres/versao_completa/pm15.pdf>. Acesso em: 24/fev/2019.

PANTOJA, V. M. L.; PEREIRA, J. M. Grandes projetos e populações tradicionais na Amazônia: a Suzano Papel e Celulose no Maranhão.Revista de Ciências Sociais-Política e Trabalho, v. 1, n. 45, 2017.

OLIVEIRA, A. B.; PEREIRA, J. M.; NASCIMENTO, A. A. Cadeia produtiva de papel e celulose e transformações recentes no sudoeste maranhense. InterEspaço: Revista de Geografia e Interdisciplinaridade, v. 4, n. 12, p. 135-154, 2018. 10.18764/2446-6549.v4n12p135-154

RETTMANN, R. Redução do desmatamento na Amazônia por meio da intensificação da pecuária em assentamentos de reforma agrária. 2013. 109 f. Dissertação (Mestrado em Desenvolvimento Sustentável, área de concentração em Política e Gestão Ambiental) Centro de Desenvolvimento Sustentável. Universidade de Brasília, Brasília, 2013.

RIVERO, S.; ALMEIDA, O.; ÁVILA, S.; OLIVEIRA, W. Pecuária e desmatamento: uma análise das principais causas diretas do desmatamento na Amazônia. Nova economia, v. 19 , n. 1, p. 41-66, 2009. 10.1590/S010363512009000100003. 
SANTOS, L. S. E.; QUEIROZ, T. M. Análise comparativa entre o desmatamento, área plantada, Produção e produtividade das culturas agrícolas do estado de Mato grosso. ENCICLOPÉDIA BIOSFERA, Centro Científico Conhecer, Goiânia, v.10, n.18; p. 950- 960, 2014.

SEMA. Secretaria de Estado do Meio Ambiente e Recursos Naturais. Plano de ação para prevenção e controle do desmatamento e das queimadas no estado do Maranhão, São Luís, 2011. Disponível em: <http://www.fundoamazonia.gov.br/export/sites/default/pt/.ga lleries/documentos/prevencao-e-controle-do-

desmatamento/Plano_Estadual_Maranhao.pdf >. Acesso em: 28/fev/2019.

SUDAM. Superintendência do Desenvolvimento da Amazônia. Boletim Amazônia indicadores socioeconômico ambientais e análise conjuntural da Amazônia legal. Disponível em: <http://www.sudam.gov.br/conteudo/destaques/arquivos/bolet im-amazonia-n02-2016.pdf>. Acesso em: 10/fev/2019.

VERÍSSIMO, A., PEREIRA, D. Produção na Amazônia Florestal: características, desafios e oportunidades. Parcerias Estratégicas, v. 19, n. 38, p. 13-44, 2015. 